\title{
Choice of Airport in Extinguishing Wildfires: Model and Cases
}

\author{
Louise Ekström and Christine Große $\mathrm{e}^{\mathrm{a}}$ \\ Department of Information Systems and Technology, Mid Sweden University, Holmgatan 10, Sundsvall, Sweden
}

Keywords: $\quad$ Balanced Transportation Problem, Wildfire, Regional Airport, Flying Forces, Real-life Application.

\begin{abstract}
This paper develops a model to support the optimal choice of an airport as a base for the flying vehicles that are operated to extinguish wildfires and forest fires. Based on experiences from the two largest wildfires in Swedish history, this study models the optimisation as a balanced transportation problem. In both cases, the model selected the airport that is closest to the fire area. If the capacity of the chosen airport was insufficient to host all of the flying vehicles, then the model added a second airport which is also nearby the wildfire area. The cases demonstrate that the total cost of the operation is lower when the extinguishing work is concentrated in an area that has a short distance between the airport and the fire, the fuel depots and the pilots' accommodation. Improved access to relevant data in the context of crisis management by air could allow for the inclusion of additional parameters and correct data in the optimisation model, which could in turn provide more comprehensive decision-making support.
\end{abstract}

\section{INTRODUCTION}

Sweden consists of large forest areas, and woodland comprises about $65 \%$ of the land area in the country. A considerable number of wildfires occur in Sweden each year, while severe forest fires emerge only once or twice per decade (Hansen, 2003). However, in a recent five-year period, two years witnessed heavy wildfire seasons. In the summer of 2014, a large wildfire occurred in Surahammar in the county of Västmanland in Sweden. This fire destroyed about 14,000 hectares of forest (Länsstyrelsen i Västmanlands län, 2014). Four years later, in 2018, several large forest fires emerged throughout the Swedish countryside. Many of them were difficult to address because of the extent, location or scarcity of resources. The four largest areas on fire were in the Swedish counties of Gävleborg, Dalarna, Jämtland and Västernorrland. These fires covered a total area of more than 18,000 hectares (MSB, 2018).

To extinguish such large wildfires, firefighting operations require many resources, such as trained personnel, proper equipment and water. One of the most effective resources for extinguishing forest fires are the flying forces (Coen, 2008). These forces include airplanes for extinguishing fires as well as helicopters from civil organisations, public sources and civil protection organisations of other countries.
Because of the vast distances and extent of roadless areas in Sweden, the distances between airports and wildfire sites significantly affect the economic losses that accompany wildfires. Therefore, the selection of an airport as a base for co-ordinating firefighting activities impacts not only societal security but also the cost of the fire extinguishing work and the economic loss due to burned woodland.

In view of this, the aim of the present study is to develop a model that supports the selection of the optimal airport to act as base for flying resources during fire extinguishing operations. To select the ideal airport or combination of airports, this study examines a balanced transportation problem that minimises the cost of fire extinguishing.

The remainder of the article is structured as follows. Following this introduction, Section 2 briefly outlines air-based firefighting practices as well as previous research on the topic. Then, Section 3 describes the construction of the model, including the assumptions and delimitations. In addition to presenting the applied data from two wildfires in Sweden, Section 4 provides the results and discusses certain implications. The conclusion summarises the article and indicates areas for improvement and further research.

https://orcid.org/0000-0003-4869-5094 


\section{BACKGROUND}

\subsection{Air-based Firefighting}

Flying forces are effective and efficient because they perform aerial firefighting that can approach remote areas that are difficult to access with land-based resources. In addition, airplanes and helicopters can quickly transport a large amount of water to the site of the fire and unload it from an overhead position. Such vehicles can collect water from a lake or other watercourse in the surrounding area without landing. Sweden currently maintains no flying resources that are entirely dedicated to firefighting. Instead, such resources are borrowed from several partners in the public and private sectors at both the national and international levels, including from other countries in the European Union, such as France, Italy, Spain and Germany. Helicopters are also loaned by civil and private organisations, the military or even other countries (Hansen, 2003).

In the practice of fire extinguishing by flying resources, regional airports provide bases at which the flying forces can, for example, receive service, refuel and access parking. To fulfil this role, airports must meet several requirements, such as an adequate capacity for the airplanes and helicopters which will be used for firefighting. In addition, they must maintain access to fuel, support lodging for pilots and staff, and provide the necessary service and logistics for the flying resources.

Another factor that influences the selection of an airport as a base for fire extinguishing is its location in relation to a particular wildfire area. From a strategic point of view, it appears relevant to use an airport that is centrally located in relation to interdependent infrastructures and services as well as proximal to site of the fire, as such characteristics can reduce irrelevant flight time. Since airplanes and helicopters for firefighting are rather slow-flying vehicles, the distance between the airport and the wildfire significantly affects the flight time. These conditions encourage the selection of an airport that is located as close as possible to the wildfire area.

\subsection{Previous Research}

There are many studies in the field of wildfires and fire extinguishing. For example, previous research has examined effective and efficient strategies for firefighting operations (Mendes, 2010). Other research has investigated the performance of such operations and identified areas for improvement in these approaches (Coen, 2008). Moreover, some studies have developed models for risk analysis to analyse the extent of the risk of a wildfire in certain areas and, on this basis, create prognoses that can support decisionmakers in planning risk reduction strategies and crisis management (Ekström, 2003; Pandey and Ghosh, 2018). In the context of firefighting operations in forest areas, another study has explored how to optimise the combination of different resource types (Donovan and Rideout, 2003).

Previous research has also targeted other societal sectors to examine optimised resource allocations. For example, in the context of emergency medical care, studies have applied decision models to investigate ideal locations for rescue services (Yang et al., 2007) or appropriate allocation of resources to various stations to reduce response time while achieving maximum area coverage (Liu et al., 2017; McCormack and Coates, 2015). In this context, Liu et al. (2017) have considered which rescue service stations to utilise as well as how many vehicles to place at the stations to reduce stand-by costs and increase the efficiency of emergency response.

Several studies on wildfires have applied simulation and optimisation approaches to determine how to allocate resources of various types. Their aim has been to support preparatory emergency response planning to facilitate firefighting operations that are as effective as possible in the event of a wildfire (Lan et al., 2011; Rodríguez-Veiga et al., 2018). Many studies have focused on preparatory emergency response in terms of, for instance, where to place airplanes for fire extinguishing in advance to reduce stand-by costs. Such studies have assessed at which airport to station the airplanes to decrease the response time and the distance to areas that have a high risk of wildfires (Bilbao Marón, 2013; Fiorucci et al., 2005). Bilbao Maróns (2013) has conducted forecasts that identify areas with a higher risk of forest fires and account for the airport capacity and distance to a potential fire to determine the optimal solution.

However, few studies have examined the ideal placement of flying resources to minimise costs during a wildfire which must be extinguished by flying resources. This study addresses this gap by considering examples from the major wildfires in Sweden in 2014 and 2018 and examining the issue as a balanced transport problem. It ultimately proposes a model for the selection of airports as bases for firefighting by flying forces. 


\section{MODELLING OF THE TRANSPORTATION PROBLEM}

\subsection{Foundations}

A transportation problem is a specific minimum-cost flow problem (MCFP) for determining the optimal solution to a problem. The method is popular because it can be applied in several ways and to many domains (Sonia, 2012).

A MCFP sends a flow from a number of supply nodes to one or several demand nodes through the arcs in a network at the lowest possible total cost (Sonia, 2012). The subject of a transportation problem is often cargo that moves alongside the arcs. Each supply node provides a restriction to the amount of goods that it can supply, while the demand nodes have a limit to the minimum amount that they must receive. If the total demand and total supply are equal, then the problem is called a balanced transportation problem.

The arcs between the nodes specify how the goods can be transported. In addition, each arc in the network reports the cost of shipping the goods between the connected supply and demand node. At times, arcs can demonstrate a constraint to the number of units that can be transported via the specific arc.

A solution for this problem indicates the number of units that can be transported on each arc. A general formulation can be created to minimise the total cost for the particular transportation problem. In addition to such general formulation, sets of constraints aim to ensure that the provided solution does not exceed the maximal possible supply and simultaneously fulfils the demand as fully as possible (Winston, 2004).

This paper applies an optimisation model in the form of a transport problem to examine the optimal airport or combination of airports to act as a base for fire extinguishing by flying forces. The following section describes the model and its particular delimitations and assumptions.

\subsection{Model and Conditions}

\subsubsection{Mathematical Model}

This section details the mathematical model for the optimisation. Equation 1 presents the objective function that minimises the total cost of the transportation problem, while Equations 2 and 3 specify the constraints. Table 1 outlines the sets, variables and parameters that appear in the model.
Table 1: List of sets, variables and parameters.

\begin{tabular}{cl}
\hline Term & \multicolumn{1}{c}{ Description } \\
\hline$f \in F$ & Set of flight vehicle types \\
$a \in A$ & Set of airports \\
$z$ & Total cost that is minimised \\
$x_{f a}$ & Number of flying vehicles of type $f$ at airport $a$ \\
$p_{f a}$ & Cost for parking flying vehicles of type $f$ at airport $a$ \\
$k_{a}$ & Capacity of airport $a$ \\
$d_{a}$ & Distance from airport $a$ to the forest fire \\
$e_{a}$ & Distance from airport $a$ to the nearest city \\
$s_{a}$ & Distance from airport $a$ to the stock of aviation fuel \\
$t$ & Total number of flying vehicles in use \\
$b$ & Total number of transports to fulfil demand of \\
& aviation fuel during the extinguishing operation \\
$c_{f}$ & Fuel consumption of flying vehicles of type $f$ \\
$l$ & Fuel consumption of trucks transporting aviation fuel \\
$m$ & Fuel consumption of vehicle transporting pilots \\
$n$ & Price of aviation fuel \\
$o$ & Price of diesel
\end{tabular}

First, the following model accounts for several aspects, such as the cost of storing the vehicles at an airport, the cost of flying to approach the wildfire and to return to the airport, the cost of transporting pilots between the airport and their accommodation, and the cost of transporting aviation fuel to the airport.

$$
\begin{gathered}
\min z=\sum_{f \in F} \sum_{a \in A} x_{f a} \\
\cdot\left(p_{f a}+2 n c_{f} d_{a}+4 m o e_{a}+b l s_{a}\right)
\end{gathered}
$$

The model applies the constant 2 , which conveys that the cost of flying appears twice: first when airplanes or helicopters fly to the fire and again when they return to the airport. The constant 4 indicates that there are two routes for land-based transport of pilots and staff - the route from the airport to the city in which their accommodation is located and the return route-and that there at least two pilots for each flying vehicle.

Second, two constraints are formulated to frame the transportation problem.

$$
\begin{gathered}
\forall a \in A ; 0 \leq x_{f a} \leq k_{a} \\
\sum_{f \in F} \sum_{a \in A} x_{f a}=t
\end{gathered}
$$

As Equation 2 demonstrates, the first constraint indicates that the number of flying vehicles that are placed at an airport cannot be less than zero or greater than the maximal capacity of the airport. Equation 3 states that the sum of the flying vehicles that are stationed at all airports must be equal to the total 
number of vehicles that are in use during firefighting operations.

\subsubsection{Delimitations and Assumptions}

The model development focused solely on costeffective selection of airports in the context of wildfire extinguishing by flying forces. It considers flying resources, including airplanes and helicopters, which can collect firefighting water from a watercourse. Accordingly, it excludes other resources, such as ground-based firefighting resources. In the Swedish context, such delimitation is appropriate since the large forest areas contain few roads, which significantly hampers time-efficient emergency response by ground-based vehicles.

The model has been delimited to determine the optimal airport or combination of airports. In Section 4, two Swedish cases are used to evaluate the optimisation model. This study selected these two areas, namely Surahammar and Ljusdal, because they contended with major forest fires in 2014 and 2018, respectively. For each area, three airports are preselected that meet several requirements. First, they have the capacity to act as a base during firefighting efforts. Second, they are located near the forest fire area. In fact, two of the selected airports were utilised during fire extinguishing operations in the individual cases. Third, the airports, which are national, regional or military, are be regularly operated or classified as emergency response airports. This selection is based on the assumption that such airports provide adequate facilities and services to act as a base for crisis management in the event of a wildfire by, for example, providing infrastructure for operations management, ground service for flying vehicles and around-the-clock manning. This third requirement implies that closed or privately owned airports are not considered. The preselected airports are StockholmVästerås Airport, Sundsvall-Timrå Airport, UppsalaÄrna Airport, Åre-Östersund Airport and Örebro Airport.

\section{CHOICE OF AIRPORTS: TWO SWEDISH CASES}

\subsection{Context and Data from Wildfires in Surahammar and Ljusdal}

This study applies the optimisation model to two Swedish cases, namely Surahammar and Ljusdal. Major wildfires occurred in both areas in recent years. In 2014, a major wildfire raged in the area of
Surahammar and developed into the largest forest fire in Swedish history at the time (Länsstyrelsen i Västmanlands län, 2014).

In 2018, a combination of heat and drought caused even more extensive wildfires. These fires burned more than 25,000 hectares of forest, which corresponds to almost twice the area that was on fire in 2014. Compared to the 110 wildfires that occur in an average season, more than 500 fires were detected by the rescue service in the summer of 2018 (Sjökvist et al., 2019). The most severe fires were concentrated in the middle of Sweden, and the area of Ljusdal was heavily affected (Ljusdals kommun, 2018). Aviation - and, thus, the regional airports - had a crucial role in combatting the forest fires.

Surahammar is located near several airports and cities, including the Swedish capital, whereas Ljusdal is situated further north at a greater distance from cities and airports.

Apart from airports that are located nearby Surahammar and Ljusdal, the pre-selection of airports for the optimisation included those that were used during the extinguishing operations in 2014 and 2018, respectively. During the wildfire of Surahammar, Stockholm-Västerås Airport (MSB, 2015) was the base for the flying forces. In addition, this study preselected Örebro Airport and the military airport Ärna in Uppsala, Sweden, which fulfil the requirements in Section 3.2.2. During the wildfire in Ljusdal, Örebro Airport was the base for the flying resources. This study also added the airports of Åre-Östersund and Sundsvall-Timra to the optimisation because they meet the aforementioned criteria and are classified as airports for emergency response.

The calculations apply data from public reports regarding the extinguishing work, public statistics in the context of aviation and a well-founded estimate of completing aspects.

In the most intensive phase of the firefighting, 14 helicopters and four airplanes were used (Ljusdals kommun, 2018; Länsstyrelsen i Västmanlands län, 2014). In the first case, airplanes were operational on 1,533 occasions, and the number of helicopter operations was estimated three times as high as the airplane operations. Airport capacity estimates were based on the number of operations per flying vehicle and the possible number of flights from the airport in accordance with public statistics from the Swedish Transport Agency (Transportstyrelsen, 2019). The airport capacity was determined by dividing the number of operated flights per day by the number of operations per flying vehicle.

The calculation of staff transport between the accommodations and airports included the fuel 
consumption of a minivan of the type Renault Traffic. The transport of aviation fuel was based on fuel consumption data for a truck of the type Scania S 500. Since the public reports do not include any details regarding the type of helicopter, this study assumes that they were Blackhawk UH-60 aircrafts, which the Swedish military operates. Aviation fuel consumption was based on estimates (e.g. Military Advantage, 2019). The airplanes for fire extinguishing were Canadair CL-415 airplanes (MSB, 2018). The municipality of Ljusdal has stated that the wildfire was under control after a period of 21 days. This most intensive phase in the second case was of approximately the same duration as the fire in 2014.

Other operational costs, such as those to land and park at the airports, were collected from the pricelists of the respective airports (Sundsvall-Timrå Airport, 2015; Swedavia Airports, 2019; Örebro Airport, 2014). Stockholm-Västerås Airport applies Swedavia's pricelist, whereas the state-owned military airport of Uppsala-Ärna has not provided any public prices. For the latter airport, this study estimated the cost to be half of the lowest fees that were specified by Stockholm-Västerås Airport. To calculate the cost, the landing fees were multiplied by the number of days of firefighting and the weight of the flying vehicle. Parking fees reflect 24 hours.

The distance between the airport and a nearby city for the accommodation of pilots was based on data from Google Maps, which offered the fastest connection. It remains uncertain which fuel depots the airports use to refill their aviation fuel storage, but this study selected Bromma Airport as the starting point for the aviation fuel supply. The distances between the airports and the two fire areas were set to the linear distance between the respective airport and the centrum of the fire-affected area according to reports. The cost of aviation fuel was collected from Hjelmco Oil (2017).

\subsection{Results and Analysis}

\subsubsection{Case One: Surahammar (2014)}

The optimisation model suggests that all airplanes and helicopters that perform fire extinguishing work should be placed at Stockholm-Västerås Airport to realise the lowest possible cost. The model calculates the total cost to be slightly more than 1 million Swedish kroner (SEK). During the forest fire in 2014, Stockholm-Västerås Airport served as the base for the firefighting activities by air. The results of this optimisation model confirm that the selection of
Stockholm-Västerås Airport was the optimal decision with regard to the cost of the operations for three reasons: it is closest to the area, it is the shortest distance from the nearest city, and it has the capacity for all flight vehicles.

\subsubsection{Case Two: Ljusdal (2018)}

The application of the optimisation model to the case of Ljusdal returned a total cost of slightly more than 2.5 million SEK. For this case, the model identified a combination of two airports as the optimal solution. Specifically, all airplanes should be placed at Sundsvall-Timrå Airport, while the helicopters should be stationed at two airports, namely Sundsvall-Timrå and Åre-Östersund. Since none of the airports has the capacity to host all of the firefighting helicopters, these aircrafts must be placed at two airports. Sundsvall-Timrå Airport should be filled with as many helicopters as possible, and the remaining helicopters should be stationed at ÅreÖstersund Airport. In this case, the model still recommends the airport that is closest to the wildfire as the host for the airplanes, as it is the most expensive factor in fire extinguishing operations.

The model did not suggest Örebro Airport as the optimal choice for the flying resources in the second case, which implies that the decision to use this airport as the base for the extinguishing work in 2018 was not optimal. This result validates the criticism that officials from the rescue service expressed following the event. They noted, for instance, that the choice was ineffective because of the significantly greater distance of Örebro Airport from the fire area compared with Sundsvall-Timrå Airport. In departing from the choice in 2018 to locate all airplanes at Örebro Airport, the optimisation model returned an increase in the total cost to slightly over 3.5 million SEK. This result demonstrates that the total cost of the fire extinguishing work could have been substantially lower if the airplanes had been moved to Sundsvall-Timrå Airport instead. Discussions of this issue occurred as the firefighting was ongoing, but they produced no consequences for the operation. One reason for the utilisation of Örebro Airport as the operational base could be that the airplanes were already stationed there and ready to participate in firefighting operations. At the beginning of the summer, the Swedish Civil Contingencies Agency (MSB) sent a request to the European Union for the placement of fire airplanes in Sweden with the preventive purpose of enabling rapid emergency operations (MSB, 2018). When the international flying forces arrived, they were placed at Örebro 
Airport, which was probably because it is centrally located in the country. Even if aircrafts were located at Örebro Airport before they started the extinguishing operation in Ljusdal, they should have been moved to a closer airport during the operation. In view of these results, the idea to move the base for the flying resources further north should have been considered at an earlier stage once it became clear that the forest fire was difficult to control and extinguish. Such movement could have reduced the cost of the extinguishing work.

\section{IMPLICATIONS FOR AIR-BASED FIRE EXTINGUISHING}

In general, an appropriate preparedness is necessary to host airplanes and helicopters at several airports in all regions of Sweden and especially during the summer period, when the risk of wildfires is high.

As the 2018 case of Ljusdal reveals, the aircrafts that carried out the fire extinguishing work should have been hosted at an airport that is closer to the fire area as opposed to Örebro Airport. Although such preparedness may generate costs, the results of the optimisation model indicate that preparedness can provide a benefit to society by saving time and, in turn, decreasing the loss of economic value. Such operational preparedness further includes proper cooperation and co-ordination between airports, pilots and the MSB, which can be difficult to maintain.

The proposed model of the transportation problem is rather simple, and it poses some advantages and disadvantages in comparison to more complex models. First, the model deliberately neglects many real-life constraints, which is mainly due to the scarcity of publicly available data about the Swedish cases. Despite such limitations, the model not only emphasises the importance of airports as critical infrastructure but also exemplifies the benefit of formal methods for decision-making in the context of crisis management to, for example, select the optimal airport for extinguishing operations. The simplicity of the proposed model therefore facilitates its application to a particular case. Nevertheless, the presented model could be improved. For instance, developments could consider fees for landing and air traffic control at the included airports, the stand-by costs of airports for facilitating a swift establishment of operation management, labour costs for all personnel who relate to a certain operation and other costs that are relevant to the logistics and administration of the operation.
The proposed optimisation model can support decisionmakers in their assessment of which airport to choose for operations. Such assessment would then use data about the actual area. This study relied on data about the forest fires in Surahammar and Ljusdal, Sweden. In the context of these cases, some data were available, but well-founded estimates were applied for certain parameters, such as airport capacity. This study experienced information scarcity in regard to several important factors. Such data and information must be available to researchers and decisionmakers to heighten the quality of decisions about firefighting operations by air. Access to relevant data is a precondition to yield more accurate and insightful results from the suggested optimisation model.

The design of the model considers the distance to the fire as a key parameter. However, the use of additional parameters is recommended to gain a more nuanced understanding of the factors that affect the choice of the airport. The model could provide a more detailed and realistic result if it includes more parameters and weights for the different parameters. Such weighting can indicate that one parameter is considered more important than another and is thus preferred at a certain cost. The experiences from the wildfires in Sweden reflect that factors beyond the distance to the fire, the nearest city or the stock of aviation fuel can affect the decision of which airport to use for operations during fire extinguishing efforts. Therefore, further improvements to the optimisation model can include aspects concerning time or geographical coverage.

The incorporation of a risk analysis could also enhance the model application. The choice of airport assumes that resources should cover large areas to ensure adequate preparation in the event of a new forest fire in another part of the area. A developed model could simultaneously consider several fire areas and use the enhanced coverage to determine the optimal base for airplanes and helicopters. The model does not account for the route of the flying resources between the wildfire and the watercourses. In the two Swedish cases, this aspect was not relevant, as the areas provided abundant resources for refilling the water tanks. However, this aspect can be significant if the model is applied to areas with a scarcity of watercourses. A model that includes this routing could then identify the optimal watercourse for the extinguishing work in the area.

Finally, the optimisation model in this study could be combined with those of previous works which have focused on the optimal placement of resources for preventative purposes. 


\section{CONCLUDING REMARKS}

This study has developed an optimisation model to select the most suitable airport to serve as a base for flying vehicles that carry out extinguishing work in the case of a wildfire. The model was applied to evaluate two Swedish cases: Surahammar in 2014 and Ljusdal in 2018. In both cases, the optimisation model primarily chose the airport that is most proximal to the site of the fire. If the capacity of the chosen airport was not sufficient to host all of the flying vehicles, then one additional airport was selected from the remaining airports that are located nearest to the wildfire. The examples demonstrate that the total cost of the fire extinguishing operation would be lower if the work is concentrated such that there is a short distance from the airport to the fire, the aviation fuel depot and the pilots' accommodation. The optimisation model provided a reliable result because it identified the same airport for the case of Surahammar that actually acted as the base for the extinguishing work in 2014. In addition, it recommended Sundsvall-Timrå Airport in the second case of Ljusdal for the lowest possible cost of the operation in 2018. Thereby, the optimisation model reveals that the actual choice of Örebro Airport as the base for the flying resources was an improper decision from a cost perspective, which confirms the perceptions of officials regarding that matter.

To enhance its usefulness for relevant decisionmakers, the proposed optimisation model should be subject to improvement. For example, the model could further include the risk of wildfires occurring simultaneously in different areas or of a new wildfire arising while the extinguishing work is still ongoing in some areas. Future analyses could consider a larger number and variety of airports and flying vehicles or extend the model to include ground-based resources. In addition, the surrounding conditions and their effects on the optimisation should be a topic of further research. Examples include the potential rationing of refuel, necessary availability of both communication services for the operative crisis management and maintenance services for flying vehicles, and staffing of the different functions that relate to the transportation by air. The latter also encompasses issues such as regular staff changes and recreation possibilities during longlasting operations, such as wildfire extinguishing efforts.

The optimisation model and result accuracy could significantly improve if data and information are publicly available. Heightened access to relevant data in the context of crisis management by air could allow for the inclusion of additional parameters and correct data in the optimisation model, which can in turn provide more comprehensive decision-making support.

\section{REFERENCES}

Bilbao Marón, M. N. (2013). Advanced Meta-Heuristic Approaches and their Application to Operational Optimization in Forest Wildfire Managment. Dissertation, Universidad de Alcalá.

Coen, D. (2008). Släckning av skogsbränder. D-uppsats, Luleå Tekniska Universitet, Luleå.

Donovan, G. H., and Rideout, D. B. (2003). An Integer Programming Model to Optimize Resource Allocation for Wildfire Containment. Forest Science, 49(2), 331335.

Ekström, F. (2003). Riskmodell för uppkomst av skogsbränder Pilotstudie $i$ Arvika kommun. Kandidatuppsats, Luleå Tekniska Universitet, Luleå.

Fiorucci, P., Gaetani, F., Minciardi, R., and Trasforini, E. (2005). Forest Fire Dynamic Hazard Assessment and Pre-operational Resource Allocation. IFAC Proceedings Volumes, 38(1), 91-96.

Hansen, R. (2003). Skogsbrandsläckning. Karlstad: Räddningsverket; Sverige.

Hjelmco Oil (2017). Prislista på smörmedel mm för kolvmotorer vid samtidigt leverans av flygbränsle. Retrieved November 22, 2019, from http://www.hjelmco.com/upl/files/147656.pd.

Lan, C.-H., Chuang, L.-L., and Chen, Y.-F. (2011). Optimal human resource allocation model: A case study of Taiwan fire service. Journal of Statistics and Management Systems, 14(1), 187-216.

Liu, M., Yang, D., and Hao, F. (2017). Optimization for the Locations of Ambulances under Two-Stage Life Rescue in the Emergency Medical Service: A Case Study in Shanghai, China. Mathematical Problems in Engineering, 1-14.

Ljusdals kommun (2018). Fakta om bränderna. Retrieved November 22, 2019, from https://www.ljusdal.se/ samhallegator/krisochsakerhet/informationombrandern a2018/faktaombranderna.4.12be7f0e165140d0d1895a 64.html.

Länsstyrelsen i Västmanlands län (2014). Skogsbranden $i$ Västmanland 2014. Retrieved November 22, 2019, from https://www.lansstyrelsen.se/download/18.2887 c5dd16488fe880d46367/1536585741018/Dokumentati on-Skogsbranden-2014.pdf.

McCormack, R., and Coates, G. (2015). A simulation model to enable the optimization of ambulance fleet allocation and base station location for increased patient survival. European Journal of Operational Research, 247(1), 294-309.

Mendes, I. (2010). A theoretical economic model for choosing efficient wildfire suppression strategies. Forest Policy and Economics, 12(5), 323-329. 
Military Advantage (2019). UH-60A/L Black Hawk Helicopter. Retrieved June 18, 2019, from https://www.military.com/equipment/uh-60a-1-blackhawk.

Pandey, K., and Ghosh, S. K. (2018). Modelling of Parameters for Forest Fire Risk Zone Mapping. ISPRS - International Archives of the Photogrammetry, Remote Sensing and Spatial Information Sciences, XLII-5, 299-304. Retrieved June 18, 2019.

Rodríguez-Veiga, J., Ginzo-Villamayor, M., and CasasMéndez, B. (2018). An Integer Linear Programming Model to Select and Temporally Allocate Resources for Fighting Forest Fires. Forests, 9(10), 583.

Sjökvist, E., Abdoush, D., and Axén, J. (2019). Sommaren 2018: - en glimt av framtiden? [The summer 2018 - a glimpse of the future?] (Klimatologi No. 52). Swedish Meteorological and Hydrological Institute..

Sonia (2012). Flow constrained minimum cost flow problem. OPSEARCH, 49(2), 154-168.

Sundsvall-Timrå Airport (2015). Airport Charge. Retrieved June 18，2019， from http://www.sdlairport.se/ download/18.33e36c11650bb1fc719d575/1533796484 683/Pricelist_aug2018.pdf.

Swedavia Airports (2019). Airport Charges \& Conditions of Services. Retrieved June 18, 2019, from https://www.swedavia.se/globalassets/flygplatsavgifter /airport-charges-and-conditions-of-services2019 20181219.pdf.

Swedish Civil Contingencies Agency (MSB) (2015). MSB:s stöd vid skogsbranden $i$ Västmanland 2014 . utvärdering. Retrieved November 22, 2019 from https://rib.msb.se/filer/pdf/27590.pdf.

Swedish Civil Contingencies Agency (MSB) (2018). MSB:s arbete med skogsbränderna 2018: Tillsammans kunde vi hantera en extrem skogsbrandssäsong.

Transportstyrelsen (2019). Flygplatsstatistik 2018. Retrieved March 08, 2019, from https://www.transportstyrelsen.se/sv/luftfart/statistik/fl ygplatsstatistik-/.

Winston, W. L. (2004). Operations research: Applications and algorithms (4. ed., internat. student ed.). Belmont, Calif.: Brooks/Cole-Thomson Learning.

Yang, L., Jones, B. F., and Yang, S.-H. (2007). A fuzzy multi-objective programming for optimization of fire station locations through genetic algorithms. European Journal of Operational Research, 181(2), 903-915.

Örebro Airport (2014). Prislista flygplatsavgifter. Retrieved June 18, 2019, from http://orebroairport.se/ orebro-airport/om-orebro-airport/teknisk-information-gdpr/prislista-flygplatsavgifter.html. 